УДК 616.12-009.72-085.273:612.111.7:575.174.015.3 doi:10.25298/2221-8785-2021-19-5-526-531

СВЯЗЬ ПОЛИМОРФИЗМА ГЕНОВ ТРОМБОЦИТАРНЫХ

РЕЦЕПТОРОВ GPIA(C807T), GPIIA (T1565C) С АКТИВНОСТЬЮ ТРОМБОЦИТОВ И ЭФФЕКТИВНОСТЬЮ АЦЕТИЛСАЛИЦИЛОВОЙ КИСЛОТЫ У ПАЦИЕНТОВ СО СТАБИЛЬНОЙ СТЕНОКАРДИЕЙ (a) НАПРЯЖЕНИЯ

\author{
Т. П. Пронько, В. А. Снежицкий, О. В. Горчакова
}

Гродненский государственный медицинский университет, Гродно, Беларусь

Введение. Последнее время большое внимание уделяется генетическим аспектам тромбообразования. Понимание генетического вклада в функцию тромбоцитов может иметь клиническое значение для персонализированной фармакотерапии.

Цель исследования - оченка распространения полиморфных вариантов C807T гена ITGA2 и T1565C гена ITGB3, изучение их влияния на активность тромбоцитов и эффективность ацетилсалициловой кислоть (АСК) у пациентов со стабильной стенокардией напряжения (ССН), проживающих в Гродненском регионе.

Материал и методьл. В исследование включень 92 пащиента со ССН, 89 из них подвергались процедуре планового чрескожного коронарного вмешательства (ЧКВ), и 93 практически здоровых человека. Данные обследований (общеклинических, агрегометрии, общего анализа крови и тромбоцитарных индексов, генотипирования методом полимеразной цепной реакции) проанализированы с использованием программы STATISTICA 10.0.

Результатыл. Распространенность носительства генотипов, ассочиированных с возможной вариабельностью ответа на терапию АСК, среди паџиентов с ССН составила по полиморфному локусу С807Т гена ITGA2 - 69,6\%, по полиморфному локусу T1565C гена ITGB3 - 31,5\%, а среди практически здоровых лии - 60,2 и 37,6\%, соответственно. В группе мужчин с ССН отмечена меньшая частота СС варианта полиморфного локуса C807T гена ITGA2 по сравнению с контрольной группой мужчин ( $p=0,043)$, согласно точному критерию Фитера. Пациенты были поделены на подгруппы (ПГ), ПГ1 составили носители генотипов СС полиморфного локуса C807T гена ITGA2 и TT полиморфного локуса T1565C гена ITGB3. ПГ2 - носители генотипов CT+TT полиморфного локуса C807T гена ITGA2 и TC+CC полиморфного локуса T1565C гена ITGB3. При анализе агрегатограмм у паџиентов ПГ1 гена ITGA2 значения ASPI-test составили 23,0 [14,0; 50,5] U, в ПГ2 - 22,5 [14,5; 34,5] U, p>0,05, в ПГ1 гена ITGB3 23,0 [16,0; 38,0] U, в ПГ2 - 20,0 [14,0; 34,0] U, p>0,05.

Выводы. Не выявлено взаимосвязи между полиморфными вариантами С807T гена ITGA2 и T1565C гена ITGB3 и активностью тромбоцитов, эффективностью АСК у пациентов с ССН.

Ключевые слова: агрегация тромбоцитов, тромбоцитарные индексы, аџетилсалициловая кислота, полиморфизм генов, стенокардия.

Для цитирования: Пронько, Т. П. Связь полиморфизма генов тромбоцитарных рецепторов GPIA(C807T), GPIIIA (Т1565C) с активностью тромбоцитов и эффективностью ацетилсалициловой кислоты у пациентов со стабильной стенокардией напряжения / Т. П. Пронько, В. А. Снежиџкий, О. В. Горчакова // Журнал Гродненского государственного медицинского университета. 2021. T. 19, № 5. C.526-531. https://doi.org/10.25298/2221-8785-2021-19-5-526-531

\section{Введение}

В патогенезе сосудистых катастроф играют роль как классические факторы риска атеросклероза (мужской пол, недостаточная физическая активность, курение, злоупотребление алкоголем, семейная история коронарного атеросклероза, сахарный диабет, гиперлипидемия, артериальная гипертензия), так и функциональная активность тромбоцитов $[1,2]$. Последнее время большое внимание в литературе уделяется генетическим аспектам тромбообразования. Понимание генетического вклада в функцию тромбоцитов может иметь клиническое значение для персонализированной фармакотерапии.

Полиморфизм гена тромбоцитарного рецептора коллагена (ITGA2) C807T (rs1126643) приводит к повышенной скорости адгезии тромбоцитов, что способствует возникновению тромбофилии, особенно у людей с высоким сердечно-сосудистым риском [3]. У пациентов с 807Т вариантом может встречаться понижен- ная эффективность ацетилсалициловой кислоты (ACK) [4]. Полиморфизм гена тромбоцитарного рецептора фибриногена (ITGB3) Т1565C способствует повышенной склонности тромбоцитов к агрегации, что увеличивает риск развития сердечно-сосудистых заболеваний $[5,6,7]$. У пациентов с этим вариантом отмечается пониженная эффективность АСК [7].

Влияние полиморфных вариантов данных генов на активность тромбоцитов и развитие резистентности к АСК может иметь определенную вариабельность в зависимости от конкретного региона и популяции. Распространенность полиморфных вариантов C807T гена ITGA2 и T1565C гена ITGB3 в белорусской популяции изучена недостаточно.

Цель исследования - оценка распространения полиморфных вариантов С807T гена ITGA2 и T1565C гена ITGB3 и изучение их влияния на активность тромбоцитов и эффективность АСК у пациентов со стабильной стенокардией на- 
пряжения (CCH), проживающих в Гродненском регионе.

\section{Материал и методы}

В исследование включены 185 человек, из них 92 пациента с ССH, функциональный класс I-III, от 40 до 72 лет (средний возраст 59,4 $\pm 6,8$ года, 71 мужчина, 21 женщина), проходивших обследование и лечение на базе Гродненского областного клинического кардиологического центра и реабилитацию на базе Гродненской областной клинической больницы медицинской реабилитации. Контрольную группу составили 93 практически здоровых человека от 32 до

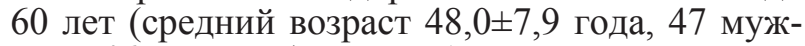
чин, 46 женщин). Все обследуемые подписывали информированное согласие на участие в исследовании.

Процедуре планового ЧКВ с постановкой стентов подвергались 89 пациентов, 3 пациентам проводилась коронарография без постановки стентов. У 60 пациентов $(67,4 \%)$ стенты были с лекарственным покрытием, у 29 (32,6\%) - без лекарственного покрытия. Все пациенты принимали бета-блокаторы (бисопролол 5-10 мг или метопролол 50-100 мг), ингибиторы АПФ (лизиноприл 5-20 мг или рамиприл 5-10 мг), статины (аторвастатин 10-20 мг или розувастатин 5-20 мг), молсидомин при болях за грудиной, АCК 75 мг, клопидогрель 75 мг. Часть пациентов (70 чел.) получали лансопразол 30 мг.

Все исследования проводились через 14 дней после ЧКВ и коронарографии.

По стандартной методике выполнялись сбор анамнестических данных, физикальное обследование, ЭКГ, эхокардиография, коронароангиография для всех пациентов с ССН, включенных в исследование.

Общий анализ крови и исследование морфометрических показателей тромбоцитов: MPV (Mean Platelet Volume) - средний объем тромбоцита, PDW (Platelet Distribution Width) - ширина распределения тромбоцитов по их объему, PCT (Platelet Crit) - тромбокрит, величина, отражающая процент объема тромбоцитов), P-LCR (Large Platelet Ratio) - процент объема больших тромбоцитов (размером более 30 фл) к общему объему тромбоцитов, проводили цитопроточным методом на автоматическом гемоанализаторе Sysmex XS-500i, Япония.

Оценку агрегации тромбоцитов проводили при помощи мультиэлектродной агрегометрии на импедансном агрегометре Multiplate (Verum Diagnostica $\mathrm{GmbH}$, Германия) с несколькими индукторами агрегации. Аденозин-5'-дифосфат (АДФ) (ADP-test) - для выявления чувствительности к клопидогрелю, арахидоновая кислота (ASPI-test) - для выявления чувствительности к АСК, пептид активатор тромбин рецепторов (Trap-6) - для отражения потенциальной способности тромбоцитов к агрегации. Высокая остаточная реактивность тромбоцитов (ВОРТ) при приеме АCK определялась по данным ASPI-test при значении AUC выше 30 U [7].
Экстракцию геномной ДНК из лейкоцитов цельной крови проводили набором реагентов «ДНК-ЭКСТРАН-1», СООО «Синтол», РФ. Молекулярно-биологическое исследование генотипов полиморфных локусов гена тромбоцитарного рецептора коллагена ITGA2 (C807T) rs1126643 и гена тромбоцитарного рецептора фибриногена ITGB3 (Leu33Pro) rs5918 проводили методом ПЦР с флуоресцентной детекцией в режиме реального времени и с применением реагентов СООО «Синтол», РФ на амплификаторе Rotor Geene, Qiagen, Германия.

Статистический анализ полученных данных выполняли с использованием пакета программ STATISTICA 10.0. Проверку на нормальность распределения проводили с помощью теста Колмогорова-Смирнова и критерия Лиллиефорса (при $\mathrm{p}<0,05$ распределение признака считали отличающимся от нормального). Полученные результаты представлены в виде среднего значения и стандартного отклонения $(\mathrm{M} \pm \mathrm{SD})$ при нормальном распределении, в виде медианы и нижнего и верхнего квартилей (Me [LQ; UQ]) при распределении, отличающемся от нормального. Две независимые группы сравнивали с помощью U-критерия Манна-Уитни. При сравнении долей (процентов) использовался точный критерий Фишера либо Difference tests. Проводился непараметрический корреляционный анализ по Спирмену. Статистически значимыми различия в группах были приняты на уровне значимости $\mathrm{p} \leq 0,05$.

\section{Результаты и обсуждение}

В таблице 1 показано распределение частоты генотипов и аллелей у исследуемых лиц.

Распределение частот генотипов генов ITGA2 и ITGB3 соответствовало ожидаемому равновесию Харди-Вайнберга как в группе контроля $(\chi 2=0,6, p=0,43 ; \chi 2=0,003 ; p=0,95$, соответственно), так и в группе пациентов с ССН ( $\chi 2=0,013$, $\mathrm{p}=0,91 ; \chi 2=0,025, \mathrm{p}=0,87$, соответственно).

Как видно из таблицы 1 , общие исследуемые группы не различались по распределению генотипов и аллелей. В группе мужчин с ССН отмечена меньшая частота СС варианта полиморфного локуса C807T гена ITGA2 по сравнению с контрольной группой мужчин $(\mathrm{p}=0,043)$, согласно точному критерию Фишера. В группе пациентов с ССН отмечена большая частота СС варианта полиморфного локуса C807T гена ITGA2 среди женщин $(\mathrm{p}=0,017)$, большая частота встречаемости аллеля $\mathrm{C}$ среди женщин $(\mathrm{p}=0,0078)$ и большая частота встречаемости аллеля Т среди мужчин $(p=0,0078)$ согласно точному критерию Фишера. Распространенность носительства генотипов, ассоциированных с возможной вариабельностью ответа на терапию АСК, среди пациентов с ССН составила по полиморфному локусу C807T гена ITGA2 - 69,6\%, по полиморфному локусу T1565C гена ITGB3 - 31,5\%, а среди практически здоровых лиц - 60,2 и $37,6 \%$, соответственно. Комбинация двух мутаций одновременно у одного человека выявлена у 20 чел. $(21,7 \%)$ из группы $\mathrm{CCH}$ и у 20 чел. $(21,5 \%)$ из группы контроля. 
Таблица 1. - Распределение частот аллелей и генотипов полиморфных локусов C807T гена ITGA2 и T1565C гена ITGB3 у обследуемых лиц

Table 1. - Frequency distribution of alleles and genotypes of polymorphic loci C807T of the ITGA2 gene, and T1565C of the ITGB3 gene in the examined individuals

\begin{tabular}{|c|c|c|c|c|c|c|c|}
\hline \multirow{2}{*}{\multicolumn{2}{|c|}{$\begin{array}{c}\text { Генотипы/ } \\
\text { аллели }\end{array}$}} & \multicolumn{3}{|c|}{ Группа ССН } & \multicolumn{3}{|c|}{ Группа контроля } \\
\hline & & $\begin{array}{c}\text { общ. группа, } \\
\text { n=92 }\end{array}$ & $\begin{array}{c}\text { муж., } \\
\mathrm{n}=71\end{array}$ & $\begin{array}{l}\text { жен., } \\
\mathrm{n}=21\end{array}$ & $\begin{array}{c}\text { общ. группа, } \\
\text { n=93 }\end{array}$ & $\begin{array}{l}\text { муж., } \\
\mathrm{n}=47\end{array}$ & $\begin{array}{l}\text { жен., } \\
\mathrm{n}=46\end{array}$ \\
\hline \multicolumn{8}{|c|}{ Полиморфный локус С807T гена ITGA2, rs1126643 } \\
\hline \multirow{3}{*}{ Генотипы } & $\mathrm{CC}$ & $28(30,4 \%)$ & $\begin{array}{c}17(23,9 \%) \\
*\end{array}$ & $\begin{array}{c}11(52,4 \%) \\
\#\end{array}$ & $37(39,8 \%)$ & $20(42,6 \%)$ & $17(37,0 \%)$ \\
\hline & $\mathrm{CT}$ & $46(50,0 \%)$ & $37(52,2 \%)$ & $9(42,8 \%)$ & $46(49,5 \%)$ & $22(46,8 \%)$ & $24(52,2 \%)$ \\
\hline & TT & $18(19,6 \%)$ & $17(23,9 \%)$ & $1(4,8 \%)$ & $10(10,7 \%)$ & $5(10,6 \%)$ & $5(10,8 \%)$ \\
\hline \multirow{2}{*}{ Аллели } & $\mathrm{C}$ & $55,4 \%$ & $50,0 \%$ & $\begin{array}{c}73,8 \% \\
\# \#\end{array}$ & $64,5 \%$ & $66,0 \%$ & $63,0 \%$ \\
\hline & $\mathrm{T}$ & $44,6 \%$ & $50,0 \%$ & $\begin{array}{c}26,2 \% \\
\# \#\end{array}$ & $35,5 \%$ & $34,0 \%$ & $37,0 \%$ \\
\hline \multicolumn{8}{|c|}{ Полиморфный локус T1565C гена ITGB3, rs5918 } \\
\hline \multirow{3}{*}{ Генотипы } & TT & $63(68,5 \%)$ & $50(70,4 \%)$ & $13(61,9 \%)$ & $58(62,4 \%)$ & $31(65,9 \%)$ & $27(58,7 \%)$ \\
\hline & $\mathrm{TC}$ & $26(28,2 \%)$ & $19(26,8 \%)$ & $7(33,3 \%)$ & $31(33,3 \%)$ & $13(27,7 \%)$ & $18(39,1 \%)$ \\
\hline & $\mathrm{CC}$ & $3(3,3 \%)$ & $2(2,8 \%)$ & $1(4,8 \%)$ & $4(4,3 \%)$ & $3(6,4 \%)$ & $1(2,2 \%)$ \\
\hline \multirow{2}{*}{ Аллели } & $\mathrm{T}$ & $82,6 \%$ & $83,8 \%$ & $78,6 \%$ & $79,0 \%$ & $79,8 \%$ & $78,3 \%$ \\
\hline & $\mathrm{C}$ & $17,4 \%$ & $16,2 \%$ & $21,4 \%$ & $21,0 \%$ & $20,2 \%$ & $21,7 \%$ \\
\hline
\end{tabular}

Примечание: * - достоверные различия между группой контроля и группой ССН, p<0,05; \#- достоверные различия между мужчинами и женщинами внутри группь, где \#-p<0,05; \#\#-p<0,01.

Tаблица 2. - Показатели агрегометрии в исследуемых подгруппах лиц со стабильной стенокардией напряжения

Table 2. - Aggregometry indices in the studied subgroups of persons with stable stenocardia

\begin{tabular}{|c|c|c|c|c|}
\hline \multirow[b]{2}{*}{ Показатели } & \multicolumn{2}{|c|}{$\begin{array}{c}\text { Полиморфный локус } \\
\text { С807T гена ITGA2 }\end{array}$} & \multicolumn{2}{|c|}{$\begin{array}{c}\text { Полиморфный локус } \\
\text { T1565C гена ITGB3 }\end{array}$} \\
\hline & $\begin{array}{c}\text { ПГ } 1 \text { (CC), } \\
\mathrm{n}=28\end{array}$ & $\begin{array}{c}\text { ПГ2 }(\mathrm{CT}+\mathrm{TT}) \\
\mathrm{n}=64\end{array}$ & $\begin{array}{c}\text { ПГ } 1(\mathrm{TT}) \\
\mathrm{n}=63\end{array}$ & $\begin{array}{c}\text { ПГ } 2 \\
(\mathrm{TC}+\mathrm{CC}) \\
\mathrm{n}=29\end{array}$ \\
\hline ASPI-test & $\begin{array}{c}23,0 \\
{[14,0 ; 50,5]}\end{array}$ & $\begin{array}{c}22,5 \\
{[14,5 ; 34,5]}\end{array}$ & $\begin{array}{c}23,0 \\
{[16,0 ; 38,0]}\end{array}$ & $\begin{array}{c}20,0 \\
{[14,0 ; 34,0]}\end{array}$ \\
\hline ADP-test & $\begin{array}{c}36,0 \\
{[22,0 ; 59,0]}\end{array}$ & $\begin{array}{c}40,5 \\
{[26,0 ; 50,0]}\end{array}$ & $\begin{array}{c}42,0 \\
{[26,0 ; 60,0]}\end{array}$ & $\begin{array}{c}39,0 \\
{[28,0 ; 47,0]}\end{array}$ \\
\hline TRAP-test & $\begin{array}{c}89,0 \\
{[78,5 ; 107,0]}\end{array}$ & $\begin{array}{c}98,0 \\
{[75,0 ; 108,0]}\end{array}$ & $\begin{array}{c}98,0 \\
{[74,0 ; 111,0]}\end{array}$ & $\begin{array}{c}94,0 \\
{[76,0 ; 111,0]}\end{array}$ \\
\hline
\end{tabular}

В общей выборке пациентов с ССН получены следующие данные агрегатограммы: ASPItest 23,0 [14,0; 37,5] U, ADP-test 40,5 [25,5; 52,5] U, TRAP-test 90,5 [75,0; 108,5] U. Выявлены 32 (34,8\%) пациента с BOPT по ASPI-test (со сниженной чувствительностью к АСК).

Для дальнейшего анализа пациенты с ССH были разделены на 2 подгруппы согласно рецессивной модели: подгруппы 1 (ПГ1) составили носители генотипов СС полиморфного локуса C807T гена ITGA2 и носители генотипа TT полиморфного локуса T1565C гена ITGB3. Подгруппы 2 (ПГ2) составили носители генотипов CT+TT полиморфного локуса C807T гена ITGA2 и носители генотипов ТС+CС полиморфного локуса T1565C гена ITGB3.

В таблице 2 представлены показатели агрегометрии у пациентов с ССH с разными генотипа- ми полиморфных локусов С807Т гена ITGA2 и T1565C гена ITGB3.

Как видно из таблицы 2, различий по показателям агрегометрии между группами не выявлено. В ПГ1 гена ITGA2 BOPT по ASPI-test выявлена у $10(35,7 \%)$ чел., а в ПГ 2 - у $22(34,4 \%)$ чел., что сопоставимо с ПГ1 $(\mathrm{p}=1,0)$. В ПГ1 гена ITGB3 BOPT по ASPI-test выявлена у 23 (36,5\%) чел., в ПГ2 у $9(31,0 \%)$ чел., что сопоставимо с ПГА $(\mathrm{p}=0,64)$.

При расчете показателей агрегометрии в зависимости от наличия комбинаций мутаций мы также не обнаружили связи между ними и чувствительностью к АСК.

В таблице 3 представлены данные общего анализа крови и тромбоцитарные индексы у пациентов с $\mathrm{CCH}$ с разными генотипами полиморфных локусов С807Т гена ITGA2 и T1565C гена ITGB3.

Как видно из таблицы 3, разницы ни по количеству форменных элементов крови, ни по характеристикам тромбоцитов между исследуемыми подгруппами не найдено. Не выявлено также влияния комбинации мутаций на исследуемые показатели общего анализа крови.

Таким образом, нами не выявлено взаимосвязи между полиморфными вариантами С807Т гена ITGA2 и T1565C гена ITGB3 и активностью тромбоцитов, эффективностью АСК у пациентов с СCH.

Согласно литературным данным, частота встречаемости мутантного аллеля $807 \mathrm{~T}$ гена ITGA2 в европейской популяции колеблется от 
Tаблица 3. - Данные общего анализа крови и тромбоцитарные индексы в исследуемых подгруппах лиц со стабильной стенокардией напряжения

Table 3. - Blood test data and platelet indices in the studied subgroups of persons with stable stenocardia

\begin{tabular}{|c|c|c|c|c|}
\hline \multirow{2}{*}{ Показатели } & \multicolumn{2}{|c|}{$\begin{array}{l}\text { Полиморфный локус } \\
\text { C807T гена ITGA2 }\end{array}$} & \multicolumn{2}{|c|}{$\begin{array}{c}\text { Полиморфный локус } \\
\text { T1565C гена ITGB3 }\end{array}$} \\
\hline & $\begin{array}{c}\text { ПГ } 1(\mathrm{CC}) \\
\mathrm{n}=28\end{array}$ & $\begin{array}{c}\text { ПГ } 2(\mathrm{CT}+\mathrm{TT}) \\
\mathrm{n}=64\end{array}$ & $\begin{array}{c}\text { ПГ } 1 \text { (ТТ) } \\
\mathrm{n}=63\end{array}$ & $\begin{array}{c}\text { ПГ2 }(\mathrm{TC}+\mathrm{CC}) \\
\mathrm{n}=29\end{array}$ \\
\hline $\mathrm{WBC} \times 10^{9} /$ л & $\begin{array}{c}6,9 \\
{[5,7 ; 8,6]}\end{array}$ & $\begin{array}{c}7,9 \\
{[6,5 ; 8,9]}\end{array}$ & $\begin{array}{c}7,3 \\
{[6,2 ; 8,8]}\end{array}$ & $\begin{array}{c}7,7 \\
{[5,7 ; 8,4]}\end{array}$ \\
\hline $\mathrm{RBC} \times 10^{12} /$ л & $\begin{array}{c}4,8 \\
{[4,5 ; 5,2]}\end{array}$ & $\begin{array}{c}4,8 \\
{[4,5 ; 5,1]}\end{array}$ & $\begin{array}{c}4,8 \\
{[4,4 ; 5,1]}\end{array}$ & $\begin{array}{c}4,9 \\
{[4,5 ; 5,0]}\end{array}$ \\
\hline $\mathrm{Hb}$, г/л & $\begin{array}{c}140,0 \\
{[133,0 ; 156,5]}\end{array}$ & $\begin{array}{c}147,0 \\
{[138,5 ; 158,0]}\end{array}$ & $\begin{array}{c}143,0 \\
{[136,0 ; 156,0]}\end{array}$ & $\begin{array}{c}150,0 \\
{[140,0 ; 158,0]}\end{array}$ \\
\hline PLT $\times 10^{9} / л$ & $\begin{array}{c}222,0 \\
{[198,0 ; 263,5]}\end{array}$ & $\begin{array}{c}225,0 \\
{[183,0 ; 252,5]}\end{array}$ & $\begin{array}{c}222,0 \\
{[184,0 ; 245,0]}\end{array}$ & $\begin{array}{c}231,0 \\
{[197,0 ; 276,0]}\end{array}$ \\
\hline MPV, фл & $\begin{array}{c}9,7 \\
{[8,3 ; 11,0]}\end{array}$ & $\begin{array}{c}9,3 \\
{[8,1 ; 10,6]}\end{array}$ & $\begin{array}{c}9,8 \\
{[8,3 ; 10,9]}\end{array}$ & $\begin{array}{c}8,8 \\
{[8,0 ; 10,0]}\end{array}$ \\
\hline PDW, \% & $\begin{array}{c}12,8 \\
{[12,0 ; 15,9]}\end{array}$ & $\begin{array}{c}12,4 \\
{[11,5 ; 13,8]}\end{array}$ & $\begin{array}{c}12,9 \\
{[11,9 ; 14,1]}\end{array}$ & $\begin{array}{c}12,2 \\
{[11,5 ; 13,1]}\end{array}$ \\
\hline PCT, \% & $\begin{array}{c}0,21 \\
{[0,17 ; 0,28]}\end{array}$ & $\begin{array}{c}0,20 \\
{[0,17 ; 0,25]}\end{array}$ & $\begin{array}{c}0,20 \\
{[0,17 ; 0,25]}\end{array}$ & $\begin{array}{c}0,22 \\
{[0,15 ; 0,26]}\end{array}$ \\
\hline P-LCR, \% & $\begin{array}{c}32,3 \\
{[26,0 ; 37,9]}\end{array}$ & $\begin{array}{c}28,9 \\
{[25,6 ; 33,5]}\end{array}$ & $\begin{array}{c}32,3 \\
{[26,2 ; 37,5]}\end{array}$ & $\begin{array}{c}28,9 \\
{[24,2 ; 31,6]}\end{array}$ \\
\hline СОЭ, мм/ч & $\begin{array}{c}12,0 \\
{[8,0 ; 21,5]}\end{array}$ & $\begin{array}{c}11,5 \\
{[7,0 ; 19,5]}\end{array}$ & $\begin{array}{c}12,5 \\
{[7,0 ; 20,0]}\end{array}$ & $\begin{array}{c}11,0 \\
{[8,0 ; 16,0]}\end{array}$ \\
\hline
\end{tabular}

37 до 47\% [3, 8], в российской популяции от 37 до $46 \%[9,10,11]$, что сопоставимо с нашими данными. Частота встречаемости мутантного аллеля 1565 С гена ITGB3 в европейской популяции колеблется от $15-16 \%[7,12]$, в российской популяции - в пределах 18-22\% [11, 13], что сопоставимо с нашими результатами.

Есть исследования, в которых авторы нашли взаимосвязь полиморфизма T1565C гена ITGB3 и C807T гена ITGA2 с аспиринорезистентностью и повышением агрегации тромбоцитов $[4,6,7$, 9]. Однако есть работы, в которых показано, что полиморфизм T1565C гена ITGB3 и C807T гена ITGA2 не предсказывает ни лабораторный ответ на аспирин, ни клинические исходы $[13,14]$, что согласуется с нашими данными.

\section{Литература}

1. Митьковская, Н. П. Нестабильная стенокардия или нестабильные коронарные синдромы? Н. П. Митьковская, О. В. Ласкина, П. Тифи // Неотложная кардиология и кардиоваскулярные риски. - 2020. - T. 4, № 2. - C. 944-977. - doi: 10.51922/2616633Х.2020.4.2.944

2. Мирзаев, К. Б. Оценка агрегации тромбоцитов в клинической практике / К. Б. Мирзаев, Д. А. Андреев, Д. А. Сычев // Рациональная фармакотерапия в кардиологии. - 2015. - Т. 11, № 1. - С. 85-91.

3. GPla Polymorphisms Are Associated with Outcomes in Patients at High Cardiovascular Risk / D. Rath [et al.] // Front. Cardiovasc Med. - 2017. - Vol. 4. - P. 52. - doi: 10.3389/fcvm.2017.00052.

4. The association of four common polymorphisms from four candidate genes (COX-1, COX-2, ITGA2B, ITGA2) with aspirin insensitivity: a meta-analysis / Z . Weng [et

\section{Заключение}

В выборке лиц Гродненского региона выявлена высокая распространенность носительства генотипов, ассоциированных с возможной вариабельностью ответа на терапию АСК как среди пациентов со стабильной стенокардией, так и среди практически здоровых лиц. В группе мужчин с ССН отмечена меньшая частота СС варианта полиморфного локуса C807T гена ITGA2 по сравнению с контрольной группой мужчин. Не выявлено взаимосвязи между полиморфными вариантами C807T гена ITGA2 и T1565С гена ITGB3 и активностью тромбоцитов, эффективностью АСК у пациентов с ССН.

al.] // PLoS One. - 2013. - Vol. 8, № 11. - e78093. doi:10.1371/journal.pone.0078093.

5. Каражанова, Л. К. Молекулярно-генетические основы диагностики и лечения ишемической болезни сердца (обзор литературы) / Л. К. Каражанова,Ш. Т. Жукушева, А. А. Чиныбаева // Наука и здравоохранение. - 2014. № 3. - C. 4-11.

6. Identification of ITGA2B and ITGB3 Single-Nucleotide Polymorphisms and Their Influences on the Platelet Function / Q. Xiang [et al.] // Biomed Res Int. - 2016. Vol. 2016. - P. 1-11. - doi: 10.1155/2016/5675084.

7. Evaluation of platelet reactivity during combined antiplatelet therapy in patients with stable coronary artery disease in relation to diabetes type 2 and the GPIIB/IIIA receptor gene polymorphism / M. Jastrzebska [et al.] // J Physiol Pharmacol. - 2019. - Vol. 70, № 2. - P. 175-185. - doi: 10.26402/jpp.2019.2.01. 
8. Prevalence of thrombosis-related DNA polymorphisms in a healthy greek population / C. Yapijakis [et al.] // In Vivo. - 2012. - Vol. 26, № 6. - P. 1095-1101.

9. Генетический маркер коллагена ITGA2 в оценке эффективности антиагрегантного эффекта препаратов ацетилсалициловой кислоты / В. И. Рузов [и др.] // Ульяновский медико-биологический журнал. - 2016. - № 1. - С. 57-64.

10. Значимость полиморфизма С807T гена рецептора к коллагену ITGA2 и агрегационной активности тромбоцитов у пациентов с артериальной гипертензией / Е. А. Шишкина [и др.] // Казанский медицинский журнал. - 2019. - Т. 100, № 3. - С. 386-391. - doi: 10.17816/KMJ2019-386.

11. Страмбовская, Н. Н. Агрегационная активность тромбоцитов у носителей генетического полиморфизма GPIA(C807T), GPIIIA (T1565C), GPIPA(C434T), Р2ГУ12(H1/H2), SELP(G1087A) тромбоцитарных рецепторов / Н. Н. Страмбовская // Бюллетень ВСНЦ CO PAMH. - 2013. - T. 94, № 6. - C. 65-70.

12. Khatami, M. Common rs5918 (PlA1/A2) polymorphism in the ITGB3 gene and risk of coronary artery disease / M. Khatami, M. M. Heidari, S. Soheilyfar // Arch Med Sci Atheroscler Dis. - 2016. - Vol. 1, № 1. - e9-e15. - doi: 10.5114/amsad.2016.59587.

13. Возможные генетические предикторы развития сердечно-сосудистых осложнений после коронарного шунтирования / Ю. И. Гринштейн [и др.] // Кардиология. - 2018. - Т. 58, № 7. - С. 77-84. - doi: 10.18087/cardio.2018.7.10148.

14. Association among P1A1/A2 gene polymorphism, laboratory aspirin resistance and clinical outcomes in patients with coronary artery disease: An updated meta-analysis / J. Wang [et al.] // Scientific Reports. - 2019. - Vol. 9, № 1. - P. 1-9. - doi: 10.1038/s41598-019-49123-y.

\section{References}

1. Mitkovskaya NP, Laskina OV, Teefy P. Nestabilnaja stenokardija ili nestabilnyje koronarnyje sindromy? [Unstable angina pectoris or unstable coronary syndromes?]. Neotlozhnaja kardiologija $i$ kardiovaskuljarnye riski [Emergency Cardiology and Cardiovascular Risks].2020;4(2):944-977. doi: 10.51922/2616633X.2020.4.2.944. (Russian).

2. Mirzaev KB, Andreev DA, Sychev DA. Ocenka agregacii trombocitov v klinicheskoj praktike [Evaluation of platelet aggregation in clinical practice]. Racionalnaja farmakoterapija $v$ kardiologii [Rational pharmacotherapy in cardiology]. 2015;11(1):85-91. (Russian).

3. Rath D, Schaeffeler E, Winter S, Levertov S, Müller K, Droppa M, Stimpfle F, Langer HF, Gawaz M, Schwab M, Geisler T. GPla Polymorphisms Are Associated with Outcomes in Patients at High Cardiovascular Risk. Front Cardiovasc Med. 2017;4:52. doi: 10.3389/ fcvm.2017.00052.

4. Weng Z, Li X, Li Y, Lin J, Peng F, Niu W. The association of four common polymorphisms from four candidate genes (COX-1, COX-2, ITGA2B, ITGA2) with aspirin insensitivity: a meta-analysis. PLoS One. 2013;8(11):e78093. doi: 10.1371/journal.pone.0078093.

5. Karazhanova LK, Zhukusheva ShT, Chinybaeva AA. Molekuljarno-geneticheskije osnovy diagnostiki i lech- enija ishemicheskoj bolezni serdca (obzor literatury) [Molecular genetic basis of diagnosis and coronary heart disease (literature review)]. Nauka $i$ zdravoohranenie [Science \& Healthcare]. 2014;3:4-11. (Russian).

6. Xiang Q, Ji SD, Zhang Z, Zhao X, Cui YM. Identification of ITGA2B and ITGB3 Single-Nucleotide Polymorphisms and Their Influences on the Platelet Function. Biomed Res Int. 2016;2016:1-11. doi: 10.1155/2016/5675084.

7. Jastrzebska M, Lisman D, Szelepajlo A, Oledzki S, Chelstowski K, Clark JS, Siennicka A. Evaluation of platelet reactivity during combined antiplatelet therapy in patients with stable coronary artery disease in relation to diabetes type 2 and the GPIIB/IIIA receptor gene polymorphism. J Physiol Pharmacol. 2019;70(2):175-185. doi: 10.26402/jpp.2019.2.01.

8. Yapijakis C, Serefoglou Z, Nixon AM, Vylliotis A, Ragos V, Vairaktaris E. Prevalence of thrombosis-related DNA polymorphisms in a healthy Greek population. In Vivo. 2012;26(6):1095-101.

9. Ruzov VI, Altenbaeva EN, Komarova LG, Nizamova LT, Kulakova JV, Vasileva IV. Geneticheskij marker kollagena ITGA2 v ocenke effektivnosti antiagregantnogo effekta preparatov acetilsalicilovoj kisloty [Genetic markers of collagen ITGA2 to evaluate the effectiveness of antiplatelet effect of the drug acetylsalicylic acid]. Uljanovskij mediko-biologicheskij zhurnal [Ulyanovsk Medico-biological Journal]. 2016;1:57-64. (Russian).

10. Shishkina EA, Khlynova OV, Vasilets LM, Sakhena V, Krivtsov AV. Znachimost polimorfizma S807T gena receptora k kollagenu ITGA2 i agregacionnoj aktivnosti trombocitov u pacientov s arterialnoj gipertenziej [Role of C807t polymorphism of ITGA2 gene of collagen receptor and platelet aggregation activity in patients with arterial hypertension]. Kazanskij medicinskij zhurnal [Kazan medical journal]. 2019;100(3):386-391. doi: 10.17816/ KMJ2019-386. (Russian)

11. Strambovskaya NN. Agregacionnaja aktivnost trombocitov $\mathrm{u}$ nositelej geneticheskogo polimorfizma GPIA(C807T), GPIIIA(T1565C), GPIPA(C434T), P2RY12(H1/H2), SELP(G1087A) trombocitarnyh receptorov [Platelet functions in healthy persons with genetic polymorphisms GPIA(C807T), GPIIIA(T1565C), GPIPA(C434T), P2RY12(H1/H2), SELP(G1087A) platelet receptions]. Bjulleten VSNC SO RAMN [Bulletin of the East Siberian Scientific Center SBRAMS]. 2013;94(6):65-70. (Russian).

12. Khatami M, Heidari MM, Soheilyfar S. Common rs5918 (P1A1/A2) polymorphism in the ITGB3 gene and risk of coronary artery disease. Arch Med Sci Atheroscler Dis. 2016;1(1):e9-e15. doi: 10.5114/amsad.2016.59587.

13. Grinshtein YI, Kosinova AA, Grinshtein IY, Subbotina TN, Savchenko AA. Vozmozhnyje geneticheskije prediktory razvitija serdechno-sosudistyh oslozhnenij posle koronarnogo shuntirovanija [Possible genetic predictors of cardiovascular complications after coronary artery bypass surgery]. Kardiologiia [Cardiology]. 2018;58(7):77-84. doi: 10.18087/cardio.2018.7.10148. (Russian).

14. Wang J, Liu J, Zhou Y, Wang F, Xu K, Kong D, Bai J, Chen J, Gong X, Meng H, Li C. Association among PlA1/ A2 gene polymorphism, laboratory aspirin resistance and clinical outcomes in patients with coronary artery disease: An updated meta-analysis. Sci Rep. 2019;9(1):1-9. doi: 10.1038/s41598-019-49123-y. 


\title{
ASSOCIATION OF POLYMORPHISM OF PLATELET RECEPTOR GENES GPIA (C807T), GPIIIA (T1565C) ON PLATELET ACTIVITY AND EFFICIENCY OF ACETYLSALICYLIC ACID IN PATIENTS WITH STABLE ANGINA
}

T. P. Pronko, V. A. Snezhitskiy, O. V. Gorchakova

Grodno State Medical University, Grodno, Belarus

\begin{abstract}
Background. Recently, much attention has been paid to the genetic aspects of thrombus formation. Understanding the genetic contribution to platelet function may have clinical implications for personalized pharmacotherapy.

The aim of the study was to assess the distribution of polymorphic variants C807T of the ITGA2 gene and T1565C of the ITGB3 gene and to study their effect on platelet activity and acetylsalicylic acid (ASA) efficiency in patients with stable angina (SA) living in the Grodno region.

Material and methods. The study included 92 patients with SA, 89 of them underwent elective percutaneous coronary intervention (PCI), and 93 were apparently healthy people. The survey data (general clinical, aggregometry, general blood count and platelet indices, polymerase chain reaction genotyping) were analyzed using the STATISTICA 10.0 program.

Results. The prevalence of carriage of genotypes associated with possible variability of response to ASA therapy among patients with SA was 69.6\% for the C807T polymorphic locus of the ITGA2 gene, 31.5\% for the T1565C polymorphic ITGB3 locus, $60.2 \%$ and $37.6 \%$ among practically healthy individuals respectively. A lower frequency of the CC variant of the C807T polymorphic locus of the ITGA2 gene was noted in the group of men with SA in comparison with the control group of men $(p=0.043)$ according to Fisher's exact test. The patients were divided into subgroups (SG). Carriers of the CC genotype of the C807T polymorphic locus of the ITGA2 gene and TT genotype of the T1565C polymorphic locus of the ITGB3 gene were in SG1. Carriers of the CT+TT genotypes of the C807T polymorphic locus of the ITGA2 gene and TC+CC of the T1565C polymorphic locus of the ITGB3 gene were in SG2. The ASPI-test values were 23.0 [14.0; 50.5$] U$ in SG1 and 22.5 [14.5; 34.5] U in SG2 of the ITGA2 gene, $p>0.05$. The ASPI-test values were 23.0 [16.0; 38.0$] U$ in SG1 and 20.0 [14.0; 34.0] U in SG2 of the ITGB3 gene, $p>0.05$.

Conclusions. No relationship was found between the polymorphic variants C807T of the ITGA2 gene and T1565C of the ITGB3 gene and platelet activity and the effectiveness of ASA in patients with SA.

Keywords: Platelet aggregation, platelet indices, acetylsalicylic acid, gene polymorphism, angina.

For citation: Pronko TP, Snezhitskiy VA, Gorchakova OV. Association of polymorphism of plate receptor genes GPIA(C807T), GPIIIA (T1565C) on plate activity and efficiency of acetyl salicylic acid in patients with stable stenocardia. Journal of the Grodno State Medical University. 2021;19(5):526-531. https://doi.org/10.25298/22218785-2021-19-5-526-531
\end{abstract}

Конфликт интересов. Авторы заявляют об отсутствии конфликта интересов.

Conflict of interest. The authors declare no conflict of interest.

Финансирование. Исследование проведено без спонсорской поддержки.

Financing. The study was performed without external funding.

Соответствие принципам этики. Исследование одобрено локальным этическим комитетом.

Conformity with the principles of ethics. The study was approved by the local ethics committee.

Об авторах/ About the authors

*Пронько Татьяна Павловна / Pronko Tatyana, e-mail: tanya pronko@mail.ru, ORCID: 0000-0003-2126-5246

Снежицкий Виктор Александрович / Snezhitskiy Viktor, e-mail: vsnez@mail.ru, ORCID:0000-0002-1706-1243

Горчакова Ольга Владимировна / Gorchakova Olga, e-mail: daniil go@inbox.ru,

* автор, ответственный за переписку/corresponding author 